\title{
Latin borrowings as a linguistic problem: approaches, reasons, typology
}

\author{
Gaziza Shoibekova - Tynyshtyk Yermekova - Aigyl Amantaevna Satbekova \\ - Sagira Odanova - Maira Malik
}

DOI: $10.18355 / X L .2020 .13 .02 .12$

\begin{abstract}
The process of activating borrowed vocabulary has become one of the significant phenomena for modern linguistics. This is due to the fact that at the turn of the 20th 21 st centuries, the borrowing of lexical units, is one of the main sources of the neogenesis of the language system. Anglicisms that have entered the recipient language entail changes that affect various levels of the language: phonetic, lexical, morphological, etc. Such phenomena are constantly under the scrutiny of linguists.

Borrowing is the most important neologization mechanism, which involves updating the structure (primarily in the case of material borrowing) and the language system (in the case of semantic borrowing). During the research on this issue where the process borrowing of a foreign word is studied, we concluded that the main point in this process is the semantic development of a foreign word and that it is necessary to separate the process of adapting a word in the speech from the process of adapting it in a language. This differentiated approach helped to study the borrowing processes in speech and in the language and made it possible to single out issues that have not been studied enough such as the degree of borrowing of a foreign language word in speech and in the language, the signs of these degrees, as well as correlation of these degrees of borrowing with speech and language.
\end{abstract}

Key words: borrowings, linguistic, problem, approaches, reasons, typology

\section{Introduction}

Despite the constant attention to the problem of borrowing in science, there are still a lot of unresolved issues, a kind of "research gap." Among the latter, there has been semantic tracing, which fits into the general process of semantic development of the vocabulary.

In particular, N.S. Arapova, S.A. Belyaeva studied the borrowing process (Arapova, 2000; Belyaeva, 1984). The study of the semantic aspect of mastering foreign words was carried out by N.V. Vaganova (Vaganova, 2001). When we study the issue of borrowings, we need to review the theory of language contacts firstly. The theory of language contact clears the situation of borrowings and demonstrates how new words appear in the language. In modern linguistics, researches pay special attention to the study of language contacts, which are the subject of a special linguistic paradigm called "contact linguistics," "linguistics of language contacts," or "linguistic contactology" (Belikov, 2006).

The specified specialization of linguistics studies the processes and results of contacting languages in a specific geopolitical space under certain historical and social conditions of communication between peoples, ethnic groups, ethnic communities, individual human groups speaking different languages (Neroznak, Pankin, 1999). The concept of "borrowed word" should be considered in two ways, differentiating the position of synchrony and diachrony. At the modern level, it seems legitimate to interpret borrowing as a foreign language unit of any degree of development and use the terms "borrowing," "foreign word," "foreign language word" as synonymous.

If we consider this issue from the perspective of time, it is possible to divide foreign units into mastered (borrowings) and undeveloped (foreign) ones. From the 
point of view of seismological mechanisms, the lexico-semantic adaptation of English borrowings is due to their paradigmatic and syntagmatic connections in the system of the recipient language, which in turn leads to the active emergence of new lexicosemantic variants of borrowed Englishisms under the influence of the language dictionary system.

Consideration of the structure of the lexical meaning of the word as a field and the use of component analysis allows us to identify various dynamic models for the development of the semantics of modern Anglicisms, among which the most productive is metonymy, less common among neo-lexemes. Along with the indicated type of semantic derivation in the semantics of English borrowings, the following processes are observed: metaphorical transfer, expansion of meaning, semantic shift, narrowing of meaning, a number of English borrowings demonstrates the complex formation of meaning (metaphor + metonymy, metonymy + expansion of meaning, semantic shift + metonia; metaphor + semantic shift, semantic shift + expansion of meaning).

Borrowing should be understood broadly, including in its composition both direct borrowing and word-formation and semantic copying of foreign language material. In this case, there is a clear correlation between the genus (borrowing) and its species (forms of borrowing). To denote a process other than semantic tracing, the term "secondary borrowing" is introduced, which seems legitimate, first of all, on the basis of the primordial / inauthenticity of the lexeme, which receives a new meaning: when tracing, the value is transferred to the material shell of the primordial words, and in case of secondary borrowing - earlier than the borrowed lexical unit.

Thus, it seems appropriate to distinguish the following genus-species components: semantic borrowing is a generic concept, it is differentiated by semantic rations and secondary borrowing, which in the language system demonstrate quite broad areas of functioning and different types of lexical meanings.

Modern linguistic science has replenished with a significant amount of theoretical data due to the emergence and development of a new branch of linguistics - neology, which studies the process of updating the language at different levels of the system. The formation of neology was due to the understanding of the new word as an independent lexical and semantic category, originally associated with borrowed vocabulary units, and subsequently expanding its conceptual and denotative basis.

The continuous updating of the lexical composition of the language makes it the object of close attention of linguists. Each stage of the replenishment of the dictionary is subjected to careful study, and the neo-lexemes included in the language are considered in various aspects, from the moment they enter the language system to the full-fledged functioning of new lexical units in someone else's vocabulary. The special attention of scientists who are concerned with the issues of neology has always been attracted by the borrowing process, as the most important mechanism of neogenesis, and also as one of the main ways of influencing the conceptual sphere of native speakers of a particular language.

Language contacts, which are an integral characteristic of any ethnocollective, have contributed to the replenishment of the language system with foreign vocabulary for many centuries. For various extra-linguistic reasons, borrowings from different languages came to the fore in different eras. The current stage is marked by the state of Englishism (or rather Americanism), which is associated with the global influence of English on world languages in general. It should be noted that the specifics of modern English language contacts are determined by a new way of borrowing - through the Internet, the possibilities of which provide researchers with rich foreign language material.

The socio-economic conditions that have arisen in the modern era have determined the special predisposition of society to the active adoption of new borrowed words, which has led to a change in the functional status of the English 
language: for the first time in the four-century history of English- language ties, the English language takes on a function, which the ancient language has always performed for the literary languages of Europe, and claims to be a per stratum, being an important donor of neo-lexemes in the field of spiritual culture, and technology.

The turn of the 20th - 21st centuries (compared with the previous century) was noted by the activation of semantic borrowings, despite the predominance of materially borrowed elements. This fact indicates the beginning of deep, semantic changes in the language as a result of transformations in the linguistic and conceptual worldviews, which requires further analysis of emerging trends, in particular, in line with the theoretical problems of perceiving foreign words, elaborated by V.V. Kolesov (2009).

The process of semantic derivation is characteristic of the last stage of borrowing development. It is noteworthy that among the main models of the indicated process, an indirect nomination comes to the fore, namely metonymic transfer (while for the native vocabulary, the metaphor is more typical). Among modern Englishisms, there have also been cases of the complex formation of a new meaning, including several semantic processes at the same time, such as metaphor and metonymy, metonymy and the expansion of meaning, etc. Thus, the indirect nomination is actively represented among new words of a foreign language, which indicates a strengthening contradiction between the information and expressive functions of the language; if we consider the numerous colloquial, jargon, simple-vernacular lexical units that actively penetrate into the standard, it can be argued that this contradiction is resolved in favor of the tendency to expressivity.

Along with direct borrowing, as noted above, semantic borrowings (secondary borrowing and semantic tracing) are actively penetrating into the modern language, demonstrating quite wide spheres of functioning. Among them, the most productive in the field of computer and Internet technologies. The process of transition of semantic borrowings from English into Kazakh is accompanied by semantic, structural, connotative transformations. The latter is the most significant since, changing the structure of mentality, they reflect changes in the national consciousness.

Of particular interest is the comparison of the types of lexical meanings of material and semantic borrowings. Whereas material borrowings are dominated by nominative non-derivative values, then semantic ones are more characteristic of figurative values (by the way, unlike material borrowings, almost all semantic borrowings develop figurative values based on a metaphor). Differences are also observed on the basis of syntagmatic relatedness: phraseologically related meanings are characteristic mainly for semantic borrowings, while paradigmatically related meanings are for material ones.

A wide representation of related lexical meanings supports vocabulary, and thereby the synthetic beginning of the language, as opposed to the analytical and agglutinative, actively developing formal lexemes. In general, we can say that the semantic influence of the English language on the modern Kazakh language is very tangible, both in the form of the semantic derivation of new material borrowings and in the form of semantic borrowings.

Undoubtedly, the study of new lexical units is of great importance in sociohistorical, cultural-cognitive and linguistic relations; This circumstance, in turn, allows us to express some considerations regarding the prospects for further research in the field of neologization in the aspect of the borrowing process. It can be predicted that the process of replenishment with new material and semantic borrowings from the indicated donor language in the near future will not reduce the rate of its intensity; Moreover, quantitative growth of semantic borrowings is possible, leading to qualitative changes in the language, which requires special attention of linguists. In

XLinguae, Volume 13 Issue 2, April 2020, ISSN 1337-8384, ISSN 2453-711X 
this regard, special attention should be paid specifically to semantic tracing, despite the difficulties associated with the identification of the named object of study. At the same time, it is possible to study this type of borrowing in terms of comparison.

Another direction in the framework of the development of this topic is the observation of connotative changes in the structure of the token under the influence of a second borrowed or traced value because it often runs counter to the usual linguistic picture of the world of the speaker and speaks of its cardinal changes. This promising direction of research, to a certain extent, echoes the possibility of a cognitive approach to semantic borrowing, which would allow us to identify relevant concepts translated into the language system.

One of the most important prospects for the study of semantic borrowings is their lexicographic description. The reflection of these units in modern explanatory dictionaries seems insufficiently complete and, in many cases, ambiguous and controversial: a lexical-semantic version of existing meanings or a homonym. It is thought that modern neography should be represented by a separate dictionary of semantic borrowings, in particular semantic cripples. The study of these areas will expand existing ideas about the semantic aspect of borrowing from the English language at the present stage. It is completely obvious that the degrees of mastering a foreign language word in speech and in the language, up to its complete assimilation, are different.

In determining the ratio of the degrees of mastery of a foreign language word in speech and in the language, the leading is the sign of semantic mastery, which is associated with the number of acquired meanings of a multi-valued word, with their interpretation and with the presence of figurative meanings. Analysis of interpretations of a foreign word in dictionaries, i.e., in language and in speech, it was possible to identify some discrepancies in the number of meanings and in the interpretation of meanings. So, twelve Englishisms from our list have a higher number of meanings in the language than ordinary native Kazakh speakers noted in the questionnaires.

These are the words drive, cool, friend, people, message, show, monitor (in the language - 2 meanings, in the speech - 1 meaning), fax (in the language - 4 meanings, in the speech - 3 meanings), sponsor (in language - 4 meanings, in speech 2 meanings), cocktail (in language - 4 meanings, in speech - 3 meanings), club (in language - 3 meanings, in speech - 2 meanings).

Some words also have differences in stylistic marks, including their absence. In most cases, this is due to the fact that dictionaries note all the meanings that these words had in the past and have at the present time, and the meanings used by different social, professional groups, and informants may not know outdated or stylistically colored meanings.

An analysis of the vocabulary entries of Anglicism and the interpretation of the meanings given by the informants made it possible to single out seven words from our list, the number of meanings in which in the language is less than in speech: grinders, chat, escape (in the language - 1 meaning, in speech - 2 values), fusion (in the language - 1 value, in the speech - 4 values), chat, sniper, jeans (in the language 2 values, in the speech -3 values).

It should be emphasized that the survey participants did not indicate any figurative meanings of those that have analyzed Anglicism. And this fact requires additional research. The analysis performed clearly showed that there are two types of relations between the degrees of development of a foreign language word in speech and in language.

Most of the analyzed Anglicisms have a direct, due to the real relationship between speech and language, the ratio of the degrees of development in speech and in language, in speech, the degree of development is higher than in the language, or the same as in the language: escape, chat, message, friend, chat, cool, drive, grinders, 
ketchup, laptop, price list, public relations, security, Internet, chips, exclusive, supermarket, image, printer, fax, show, sniper, sponsor, office, business, jeans, monitor, cocktail, jacket, bar, park, rail, station, club.

The analysis also revealed a group of Anglicisms, which, though having a direct ratio of degrees of development, deserve special attention of lexicographers, since they are not recorded in any of the dictionaries analyzed. However, in speech, they have a medium (ICQ, nickname, fashion, Oops) and highest degree of development (wow). Identified words with an inverse ratio of degrees of development, in language, the degree of mastery is higher than in speech. These Anglicism can be divided into two groups according to borrowing time.

In the first group, we combined the words that were borrowed at the end of the 20th century: fusion (in the language there is a low degree of development, and in speech, it is zero); copyright, kidnapping (in the language the average degree of development, in speech - a low degree of development); happy end (in the language the highest degree of development, in speech - a high degree of development). This indicates that the compilers of the dictionaries did not evaluate the actual degree of mastery of these words in speech.

The second group consists of Anglicisms, which were borrowed at the end of ХІХв. - 1st half of the 20th century. These are the words hall, corrugated, porch (in the language - the highest degree of development, in speech - a high degree of development). W. Weinreich characterized the adaptation of a foreign word in the receiving language in a very figurative way:

"In speech, interference is like sand carried away by the current, but in language it can be compared with the same sand that sank to the bottom of the lake. These two stages of interference must be distinguished. In speech, interference arises in the statements of a bilingual as a result of his personal acquaintance with another language. In language, we find those phenomena of interference which, due to repeated appearances in the speech of bilinguals, have become habitual and entrenched in use" (Weinreich, 2006).

At present, the causes, paths, and conditions for the penetration of foreign words into the host language have been thoroughly investigated; carried out an etymological and chronological classification of foreign words in Kazakh; The stages of the foreign language adaptation process have identified the stages of the process of adaptation of a foreign language word in the language (although there is still no complete unanimity on this issue).

One of the types of borrowing is tracing. As you know, the process of replenishing the vocabulary of the language with foreign vocabulary is carried out by material (direct) borrowing and tracing - borrowing hidden. It is noted in the scientific literature that "only the combination of these two types of borrowing gives an idea of the influence of one language on another" (Galdi, 1958). Nevertheless, at various stages of language contacting, it is possible that certain borrowed elements prevail, either tracing or materially borrowed.

There is no discussion about the classification of tracing. The first classification belongs to B. Unbegaun, who distinguishes the following types of traced units:

- lexical;

- semantic;

- phraseological;

- half tracing or borrowed (Matveeva, 2013).

However, far from all questions of the theory, tracing is solved in modern linguistics unambiguously. For example, the question of the status of tracing as borrowed lexical units remains controversial. Traditionally, linguists consider tracing

XLinguae, Volume 13 Issue 2, April 2020, ISSN 1337-8384, ISSN 2453-711X 
as a special type of borrowing (Budagov, 2014), however, drawing some boundary between these concepts on the basis that borrowing is a transfer of the exponent and the content of the mark; meaning is borrowed in tracing paper (along with the structure or whatever), the external form belongs to the borrowing language.

It is the construction of tracing from the material itself that allows some scientists to attribute tracing units to borrowed only formally.

In our opinion, the borrowing process should be understood broadly, including both direct borrowing and word-formation and semantic copying of foreignlanguage material. In this case, there is a clear correlation between the genus (borrowing) and its species (forms of borrowing). In addition, with this approach, the translated elements of a foreign language and, accordingly, the types of borrowing, including the semantic borrowing, are clearly distinguished.

By the way, the issue of distinguishing between the concepts of "semantic coding" and "semantic borrowing" is also being resolved ambiguously. The allocation of secondary borrowings, along with semantically coded units, is legitimate primarily on the basis of the sign of insubstantiality of the lexeme, gaining a new meaning, since in all traditional definitions of the term "tracing" there are components of the "original word," "elements of the receiving language," and etc.

"Tracing is used to designate borrowings in the form of a literal translation of a foreign word or expression, i.e. its exact reproduction by means of a perceiving language with preservation of the morphological structure and motivation" (Arnold,1959); "Tracing is the formation of new words and expressions according to lexical and phraseological models of another language using the elements of that language" "Tracing are borrowed words and expressions when a foreign-language sample is translated in parts by means of its own language" (Reformatorskii, 2004).

Accordingly, borrowed words that received at a certain moment of existence an additional meaning, taken from other languages, it is logical to call secondary borrowings. We came up with the following conclusions. We distinguished five degrees of mastering a foreign language word in speech, and in the language, they are zero-degree, low degree, medium degree, high degree, and highest degree.

The signs and criteria for each degree of mastering a foreign language word in speech (written and oral) and in the language are defined. A special, psycholinguistic feature has been identified that determines the degree of perception of a foreign language by ordinary carriers of the host language. The ratios of the degrees of development of a foreign language word are analyzed, and two types of ratios are distinguished:

a direct correlation of the degrees of mastery of a foreign language word (the degree of mastery of a foreign language word in speech is higher than in the language), reflecting the natural, regular process of adaptation of a foreign language word;

the inverse ratio of the degrees of mastering a foreign language word (the degree of mastering a foreign word in speech is lower than the degree of mastering in a language), which does not correspond to the natural process of adaptation of a foreign word. It is shown that the degree of mastering a foreign language word in speech and in the language does not depend on the borrowing time of this word.

However, the degree of perception of a foreign language word by ordinary native speakers as "their own" directly depends on the borrowing time: at least 100 years of active functioning of foreign language borrowing in speech is necessary so that ordinary native speakers cease to feel its foreign language and perceive this word as "their own."

The analysis of Anglicisms in the works of the different genre, in the speech of ordinary native speakers of the language and in the language (in dictionaries), indicates the need to create dictionaries of new foreign words, which would include all new foreign words that appeared in speech over a certain period (for example, over 
the past 20 years). The periodical publication of such dictionaries will make it possible to record the beginning of the process of assimilation of a foreign language word and the time of its appearance in speech, to trace the further fate of each word and establish how many of the newly appearing foreign language words in speech are further fixed in the language. This very clearly indicates the need to study the real situation with the use of English in speech and to study the attitude of ordinary native speakers of the language to the use of borrowed words so that on a reliable scientific basis, it is possible to formulate a language policy regarding English.

\section{Bibliographic references}

AKHMANOVA O.S. 2005. Dictionary of linguistic terms. In: URSS, 576 p.

BAGAN ZH. 2004. Language interference in the conditions of Franco-Congolese bilingualism: Dis. ... doc. filol. sciences. - Saratov, $350 \mathrm{p}$.

APRESYAN YU.D. 1992. Connotation as part of the pragmatics of the word (lexical and graphic aspect) // Russian: Problems of grammatical semantics and evaluation factors in the language. In: Nauka, pp. 45-64.

ARAPOVA N.S. 2000. Tracing paper in the Russian language of the post-Petrine period. Vocabulary experience. In: Moscow State University Publishing House, 319 p.

ARISTOVA V.M. 1979. English-Russian language contacts. - L.: Ed. Leningrad State University, $151 \mathrm{p}$.

ARNOLD I.V. 1959. Lexicology of modern English. In: Publishing House of Literature in Foreign Languages, $351 \mathrm{p}$.

ARUTYUNOVA N.D. 1980. To the problem of functional types of lexical meaning, Aspects of semantic research. In: Nauka, pp. 156-250.

ARUTYUNOVA N.D. 1979. Linguistic metaphor (syntax and vocabulary), Linguistics and poetics. In: Science, pp. 120-139.

BALLY S. 1961. French style. In: Foreign Literature, 393 p.

BELIKOV V.I. - KRYSIN L.P. 2000. Sociolinguistics. In: RGGU, 439 p.

BELYAEVA S.A. 1984. English words in Russian language of the XVI - XX centuries. - Vladivostok: FENU Publishing House, 108 p.

BENVENIST E. 1974. General Linguistics. In: Progress, 447 p.

BERTAGAEV T.A. 1972. Bilingualism and its varieties in the consumer system. Problems of bilingualism and multilingualism. In: Nauka, pp. 82-85.

BONDARETS O.E. 2008. Foreign borrowings in speech and in language: the linguosociological aspect. - Taganrog: Publishing House of Taganrog. State Pedagogical Institute, $142 \mathrm{p}$.

BRAGIN A.A. 1973. Neologisms in Russian. In: Education, 224 p.

BREITER M.A. 1997. Anglicism in the language: history and prospects. Ed. DialogMSU JSC, $156 \mathrm{p}$.

BUDAGOV, R.A. 2014. Language, history and modernity / R.A. Budagov. In: Moscow State University, 299 p.

KARLINSKY A.E. 1984. Problems of the theory of language contacts In: Language $\neg$ contacts and interference. - Kazan: Publ. KazGU, pp. 3-13.

KASYANOVA L.Yu. 2006. Neologization vectors in modern Russian: a monograph. - Astrakhan, 148 p.

KASYANOVA L.Yu. 2009. Cognitive-discursive problems of neologization in the Russian language of the late XX - early XXI century: Dis. ... doc. filol. sciences. Astrakhan, $401 \mathrm{p}$.

KOLESOV I.YU. 2009. Actualization of visual perception in the language: cognitive aspect: on the material of English and Russian languages: Dis. ... doc. filol. sciences. Barnaul, $467 \mathrm{p}$.

XLinguae, Volume 13 Issue 2, April 2020, ISSN 1337-8384, ISSN 2453-711X 
MATVEEVA G.G. 2013. Fundamentals of pragmalinguistics: Monograph / G.G. Matveeva, A.V. Lenets, E.I. Petrova. In: Flint, Science, 232 p.

NEROZNAK V.P. - PANKIN V.M. 1999. Linguistic contactology and language conflicts // Problems of linguistic contactology. pp. 10-23.

REFORMATORSKII A.A. 2004. Introduction to linguistics. In: Aspect Press, 518 p.

TARASOVA M.V. 2009. Semantic changes in English borrowings in Russian and German in the context of globalization: Dis. ... cand. filol. sciences. - Belgorod, $192 \mathrm{p}$. TELIA V.N. 1986. The connotative aspect of the semantics of nominative units. In: Nauka, 141 p.

TELIA V.N. 1980. Semantics of related meanings of words and their combination $\neg$ Aspects of semantic research. In: Nauka, pp. 250 $\neg 319$.

TER-MINASOVA S.G. 2007. War and the world of languages and cultures. Questions of the theory and practice of interlanguage communication. In: ACT: Astrel, $286 \mathrm{p}$.

VAGANOVA E.N. 2001. Coreference and connexon as the main properties of the semantic and structural organization of the text: On the material "story": Dis. ... cand. filol. sciences. - Nizhegorods, $426 \mathrm{p}$.

VALGINA N.S. 2006. Rosenthal D.E., Fomina M.I. Modern Russian language / Under. ed. N.S. Valgina. In: Logos, 528p.

VASILIEV L.M. 1990. Modern linguistic semantics. In: Higher School, 176 p.

VINOGRADOV V.V. 1977.The main types of lexical meanings of the word, Vinogradov V.V. Lexicology and Lexicography: Selected Works. In: Nauka, pp. 162-189.

VINOGRADOV V.V. 1982. Essays on the history of the Russian literary language of the XVII-XIX centuries. In: Higher school, $528 \mathrm{p}$.

VOLKOV A.G. - KHABAROV I.A. 1961. Ontological and epistemological aspect of the iconic problem. // Laws of semantic development in language, pp. 60-67.

VOLODARSKY E.F. 2002. Borrowing as a reflection of Russian-English contacts. Questions of linguistics. n. 4, pp.96-111.

GALDI L. 1958. Words of romance in Russian. In: Publishing house of Moscow University, $81 \mathrm{p}$.

WEINREICH U. 1979. Language contacts. Conduct and follow-up problems. Kiev, $364 \mathrm{p}$.

Words: 4493

Characters: 29084 (16,16 standard pages)

associate professor Gaziza Shoibekova

professor Tynyshtyk Yermekova

professor Satbekova Aigyl Amantaevna

associate professor Sagira Odanova

Kazakh national women's pedagogical University

050000, Almaty, ul. Aiteke bi, 99.

Kazakhstan

zurazhan88@mail.ru

Maira Malik

al-Farabi Kazakh national University

050010, Almaty, 17 al-Farabi Ave.

Kazakhstan 